\title{
Highway Capacity Estimation: International Regulation and Neurostructural Remodeling Approach
}

\author{
Anton Sysoev ${ }^{1 *}$, Tatyana Anikienko², Semen Blyumin ${ }^{1}$ \\ ${ }^{1}$ Department of Applied Mathematics, Faculty of Automation and Computer Science, Lipetsk State Technical University, \\ RU-398055 Lipetsk, Moskovskaya str. 30, Russia \\ 2 Russian Timiryazev State Agrarian University, RU-127550 Moscow, Timiryazevskaya str. 49, Russia \\ *Corresponding author, e-mail: anton_syssoyev@mail.ru
}

Received: 19 July 2018, Accepted: 27 December 2018, Published online: 28 June 2019

\begin{abstract}
Increasing number of personal vehicles and cargo transportation requires the development of a well-planned transport policy within states and states associations. The existing normative acts give different directions in the field of regulation of transportation processes. One of the most important aspects in assessing the existing state transport arteries and planning new ones is the analysis of their capacity, which could be performed in various ways. The classical approach defines capacity as a certain value that is constant for the entire period under consideration. However, this value is changing at any given point in time depending on various factors (weather, psychological, accidental), and this fact determines the stochastic nature of this indicator. The paper presents an overview of existing approaches and a perspective approach that defines capacity as a random variable. The paper also presents the method to model highway capacity, which delivers greater accuracy compared to traditional approaches used in Russia and Germany. Using the proposed approach it is possible to obtain adequate values of highway capacity, which is important in assessing the quality of the functioning of existing highways and planning new ones.
\end{abstract}

Keywords

highway capacity, transportation policy, traffic flow, transportation system, Weibull distribution, mathematical modeling

\section{Introduction}

Today the problem of transport infrastructure development, which is caused by the constant growth in the number of transportation and freight vehicles, is becoming especially acute both in the EU and in the EEA. Therefore, in the short term, modernization of the transport system is required. The President of the Russian Federation noted that lately the demand for transport services has significantly increased, but the existing infrastructure is simply unable to provide them. A large part of its facilities is no longer operational and has become technically unsuitable and morally obsolete. Speaking at the meeting of the Bureau of the State Council on Russia's transport infrastructure development, the President pointed out that with Russia's vast territory, modern advanced transport infrastructure truly is the way to progress as well as something that plays a vast strategic importance for economic growth and qualitative transition to the innovative path of development and new opportunities for domestic and international cooperation in increasing labor mobility and new communication opportunities. For this, the transport strategy of Russia, which was approved by Government Order of the Russian Federation on November 22, 2008, No. 1734-r (with correction on June 11, 2014) is adopted and implemented until 2030. The Budget Code innovations should also improve the situation, allowing to conclude state contracts for the entire period of construction of large objects.

It is worth noting that problems of Russian realities exist in other countries as well. Thus, in 2006, the EU Commission approved the revision of medium-term prospects for transport development in the EU and presented the White Book, which emphasizes common approaches for all EU countries and a cooperative dialogue on transport issues. The document also contains a plan for industry development until 2020. According to the European Commission, the main task of the development is the optimization of work of all kinds of transport. In this regard, the development of intermodal transport is of great importance. In order for the transport system to become more technologically 
advanced, it is necessary to intensively apply achievements of logistics and innovative technologies.

The purpose of this study is to analyze the aspects of regulation of sub-objectives regarding the traffic management in the EEMP and the EU on the example of two countries - the Russian Federation and the Federal Republic of Germany.

It should be noted that in most countries, transport legislation is structured according to the following scheme: a general codified act (Civil and/or Commercial Code special transport laws). However, there is no single transport code in Germany. The main provisions in this area are reflected in the following laws in the field of road transport - the highway law (Bundesfernstrassengesetz, BFernStrG 1994), transportation of people - transportation of people law (Personenbefürderungsgesetz, PersBefG, 1990), transportation of goods by car - the law of transportation of goods by car (Güterkraftverkehrsgesetz, GüKG, 1993), related to railway transport - General Railways Act (Allgemeines Eisenbahngesetz, AEG, 1993) transport on Inland waters the Federal waterways Act (Bundeswasserstrassengesetz, WaStrG, 1990) (Belyh, 2008).

In Russian Federation in the field of transport, the sectoral strategic planning document is the Transport Strategy of the Russian Federation for the period up to 2030, approved by Order of the Government of the Russian Federation of November 22, 2008, No. 1734-r, with correction by the Russian Government on June 11, 2014. № 1032-r.

In 2016, the development of transport complex industries was implemented through the state programs of the Russian Federation and was oriented towards realization of the objectives of the Transport Strategy, as well as the activities of the Business Plan of the Ministry of Transport of the Russian Federation, aimed at addressing the tasks set out in the decrees of the President of the Russian Federation on May 7 , 2012. № 596-606 and the main activities of the Government of the Russian Federation for the period until 2018.

That said, the main instrument for implementing the Transport Strategy was the State Program of the Russian Federation of April 14, 2014, No. 319, "Development of the Transport System", approved by the Government of the Russian Federation.

The main documents also include the Federal Law of November 8, 2007, № 257-FA (with correction on 05.12.2017). "On Roads and Road Activities in the Russian Federation and on Correction of Certain Legislative Acts of the Russian Federation"; Order of the Government of the Russian Federation No. 741-r of April 21, 2016 approved the allocation grants provided in 2016 from the federal budget to the budgets of the subjects of the Russian Federation for co-financing the expenditure obligations of the subjects of the Russian Federation related to the implementation of measures for the construction and reconstruction of public roads with hard surface leading from the public road network to the nearest facilities of public interest of the rural settlements, as well as to production and processing facilities and of agricultural products within the framework of the federal target program "Stable Development of Rural Territories for 2014 - 2017-nd the Period up to 2020".

The analysis of the fulfilment of the Plan of Action for the implementation of the Transport Strategy of the Russian Federation for the medium-term period (2014 2018) as of December 31, 2016 showed that activities were implemented for 140 items of the Plan of Action, including fully implemented 59 out of 224 items of the plan. 17 federal laws, 20 standards, 35 government regulations of the Russian Federation, 45 departmental normative acts were prepared and adopted, 24 research works were carried out and 9 are in the stage of implementation, and in the short term, there is still a lot more to harmonize with the EU countries in the regulations.

Considering the issue of monitoring rules and regulations according to which the existing new objects of transport systems should be modernized, it proves necessary to operate with the accepted classification of the elements of such systems. It should be noted right away that the main feature of the classification is the location of the highway. Depending on whether it is a city highway or whether it is located in the city or outside the city, different rules of the assessment of the quality of its functioning and the rules respecting the designing should be applied.

Article 5 of the Federal Law No. 257-FA "On Roads and Road Activities in the Russian Federation and on Correction of Certain Legislative Acts of the Russian Federation" defines various types of roads in Russia, namely, federal roads (for example, roads connecting the capital with the centers of the subjects of the Russian Federation, the roads connecting the cities of Russia with the cities of other states, roads providing access to airports, ports, special facilities of federal significance, etc.); roads of regional or inter-municipal importance (the criteria for categorizing a road to this classification are established at the legislative level of the Highest Executive Body of the State Power of the subject of the Russian Federation); roads of local significance (roads within the boundaries of settlements, cities, city districts with the 
exception of higher-level roads according to the hierarchy); Private roads (roads owned by private or legal entities). According to GOST R 52398-2005 "Classification of roads. Main parameters and core requirements" roads of the Russian Federation can be divided into highways, express roads and ordinary roads according to traffic conditions and access to vehicles. A distinctive feature of the roads of the first two categories is the presence along the entire length of the multi-lane of a carriageway with a central reserve, the absence of level crossings between roads, railways, tramways, bicycle and pedestrian paths, as well as the access to the road through junctions located through certain locations. At the same time, the total number of lanes for such types of roads should be at least 4 with a width of each strip of $3.75 \mathrm{~m}$.

According to the current version of the German Capacity Assessment Guide, all the roads of the Federal Republic of Germany can be divided into the following groups: highways, rural roads and urban sector roads. Each type possesses an amount of their own specific rules and management characteristics. The German "highway" (autobahn) group corresponds to the Russian classification of roads such as "highways" and "expressways". The number of lanes in each direction can vary from 2 to 4 with a width of each strip from 3.5 to $3.75 \mathrm{~m}$.

This study attempts to assess the many approaches at calculating the capacity rate of a highway (furthermore when referring to the highway, we mean the Russian category "motorway" and "expressway" or the German "highway" (autobahn) category) in Russia and Germany. In addition to classical approaches, modern methods are presented, delivering the accuracy of modelling processes on highways.

\section{The review of the literature}

The basic norms in the area of assessment of the highway quality in the Russian Federation are presented in the document "Methodological recommendations for assessing the highway capacity" (furthermore - ODM 218.2.0202012, current edition 2012) (Rosavtodor, 2012). This document, just like the American and German counterparts, defines the main ideas for studies and modernization of highways. It reviews the basic methods for estimating the road capacity, defines methods for calculating the capacity at intersections with and without traffic signalling, as well as various approaches to assessment of the complex road segment capacity; there are practical examples of calculation of the capacity.
In Germany, technical standards for design and study of highways are defined in the Capacity Assessment Guidelines (Handbuch für die Bemessung von Strassenverkehrsanlagen, HBS, current edition 2015) (FGSV, 2015). The manual consists of three parts and provides a set of practical examples of calculating various indicators of transport systems in Germany. The first part (Teil A: Autobahnen) is devoted to the construction of expressways, the second part (Teil S: Stadtstraßen) regulates the construction of city highways and the third part (Teil L: Landstraßen) describes methods for assessing the characteristics of rural highways that are not expressways.

Many ideas, in particular, the quality assessment methodology (in terms of the LOS criterion - the level of quality) of the operation of roads, are similar to the ideas presented in the American Highway Capacity Manual (HCM, current edition 2010) (TRB, 2010).

Various researchers describe different ways of modelling transport systems in general and highways in particular. For example, Rice et al. (2004) propose a method for predicting the amount of time needed to cross a highway segment using a simple model of linear multidimensional regression. This method is based on using a combination of the available back data and real-time data. Chen et al. (2003) uses the approach of fundamental curves to describe and analyze the relationship between characteristics of a traffic flow and their joint conduct in the dynamic without assuming the form of the functional link between the settings. Some authors, for example, Taylor and Meldrum (1995), Dharia and Adeli (2003), Çodur and Tortum (2015) suggest using artificial neural networks and hybrid neural models for both modelling and subsequent assessment of the characteristics of a highway segment or the entire road as a whole. It is worth noting that, although rarely used, the use of the "black box" concept is promising in relation to fulfilling these tasks.

During the highway analysis process, the average values of the traffic flow parameters prove to be the most important, so the use of mathematical models of a relatively simple structure is justified. In this regard, the most popular approach for simulating highways is the use of the public service systems.

In order to determine the public service system, it is necessary to indicate the statistical distribution of an incoming flow of request numbers (vehicles in case of a highway segment), the statistical distribution of service time, and the structure of service discipline. There are many service disciplines (for example, see Ventcel and Ovcharov, 2000), 
but for highway segments, it is only possible to apply the FCFS discipline (first-come-first-served).

The occurrence of traffic jams on highway segments could in some cases be avoided if the capacity assessment of an area under consideration is more accurately and fully performed under specific conditions. In comparison with the German Guidelines on road construction in ODM 218.2.020-2012, the idea of estimating the highway segment capacity on the basis of an analysis of the traffic volume-to-capacity ratio is also prevalent. In its first edition (Minavtodor RSFSR, 1982), the Guidelines (Soviet Guidelines) determined 5 levels of functioning efficiency (LOS) of highway segments. The current version defines a number of 6 such levels. Their comparison according to Russian and German Guidelines is presented in Table 1 (the table gives the interval values of the traffic volume( $q$ )-to-capacity(c) ratio).

The slight difference in defining the thresholds of the above relations can be explained, first and foremost, with the use of many theoretical models underlying the simulation of motion and the usage of different speed limits and modes of application, and, secondly, by differences in the culture of driving. Next, we have the key points underlying the Russian and German approaches to determining the capacity of a high-speed highway segment.

According to the concept presented in ODM 218.2.0202012, the capacity is assessed for both directions of the highway (in case of having only one lane in each direction). For highways with two or more lanes in each direction, (in case where the distribution of the traffic volume of vehicles is uneven within each of the lanes) assessment of the capacity must be performed for each of the lanes separately. Then for each of the lanes (taking into account compositions of the traffic flow, road and weather conditions) the capacity of the segment is defined as

$$
P=2\left(P_{1}+\ldots+P_{n}\right)
$$

where $P$ is the capacity of the highway segment, $P_{1}, \ldots, P_{n}$ are private lane capacities, defined as

$$
P_{i}=P_{i, \max } \cdot \sum_{j=1}^{k} \beta_{j}
$$

where $P_{i, \max }$ is the maximum capacity of the lane $i$, and $\beta_{j}$ is the reduction factors. These factors take into account the influence of convergence of the traffic flows, the geometric characteristics of the lane, the presence of suburban and urban inter-city transport. The manual presents a number of tables that determine the maximum capacity values for different conditions, as well as recommendations for
Table 1 Thresholds of the volume-to-capacity ratio defining the Level of Service (LOS) on freeway segments. Quality of the Service Level

\begin{tabular}{lcccccc}
\hline $\begin{array}{l}\text { Level of } \\
\text { Service }\end{array}$ & A & B & C & D & E & F \\
\hline $\begin{array}{l}\text { Russian } \\
\text { Capacity } \\
\text { Manual }\end{array}$ & $<0.2$ & $0.2-0.45$ & $0.45-0.7$ & $0.7-0.9$ & $0.9-1.0$ & $>1.0$ \\
$\begin{array}{l}\text { German } \\
\text { Capacity } \\
\text { Manual }\end{array}$ & $\leq 0.3$ & $0.3-0.55$ & $0.55-0.75$ & $0.75-0.9$ & $0.9-1.0$ & $>1.0$ \\
\hline
\end{tabular}

choosing the correct set of reduction factors. Intermediate values not represented in the tables can be obtained by linear interpolation.

HBS (FGSV, 2015) also contains a set of approaches for assessing the capacity of different types of roads. The current version is the second edition, in which many theoretical results are updated and aligned with current research in this field. However, as in the earlier version, a traditional deterministic approach is still used to calculate capacity.

The calculated values of the capacity of the highway segment according to HBS are based on the presence of roads adjacent to the highway, the current traffic situation and the control parameters (in case of variable speed limits). The estimated value of the capacity of the road segment is based on the use of the Aerde model (van Aerde, 1995), which relates the traffic volume and vehicle speed. Knowing the speed and the volume of the vehicles, it is possible to determine the capacity as the maximum value of the volume, which entails the coming of a traffic jam. According to this approach and the Aerde model, the binding ratio is defined as

$$
q(v)=\frac{1}{c_{1}+\frac{c_{2}}{v_{0}-v}+c_{3} \cdot v},
$$

where $q(v)$ is the volume of the motion with the velocity $v$, $c_{1}, c_{2}, c_{3}, v_{0}$ are the parameters of the model.

However, at the moment when the traffic flow changes from free movement to the jam conditions, the application of the Aerde model gives unrealistic results of estimating capacity. To avoid this, the value of maximum volume (by which the capacity is calculated) is checked for statistical consistency, based on multiple calculations. HBS (FGSV, 2015) includes tables of estimated capacity values determined by the parameters specified above. Intermediate values can also be obtained by linear interpolation.

The weak side of the above approaches (models, Eqs. (1)-(3)) is viewing the capacity of the road segment as a constant when it varies constantly and can be 
represented by some random variable having a certain statistical distribution (Blyumin et al., 2016). The following is a stochastic approach to the simulation of highway capacity, with which it is possible, based on a large number of statistical data, to obtain sufficiently accurate data on the significance of the capacity of a specific segment of the highway at a certain point in time.

\section{Materials and techniques}

Van Toorenburg (1986) firstly proposed the use of the censored data model to identify the distribution function of a random value in modelling the highway capacity. With this approach, a highway segment is treated as a D / D / 1 public service system. In this approach, all available data about the capacity rate is divided into various class intervals. An interval is called uncensored if it contains an observed capacity rate. Van Toorenburg (1986), as well as Minderhound (Minderhoud et al., 1997), suggest that the capacity rate can only be measured when there is a traffic jam caused by limited physical capabilities of a segment under current conditions. According to this approach, observations of free and jammed traffics during a traffic jam are included in the capacity rate analysis. However, according to the phenomenon described in Banks (1990), the capacity rate during a traffic jam differs from the capacity at the time preceding a traffic jam. Thus, it would be correct to include only the time intervals preceding traffic jams in the analysis of the capacity rate (Zurlinden, 2003). Therefore, the interval $i$ is classified as "uncensored" if the observed value of a traffic flow volume $q_{i}$ causes the occurrence of a traffic jam in the next interval $i+1$ (the occurrence of a traffic jam is determined by achieving an average minimum flow rate). However, if it's free at during traffic time and also free at the next moment, then such interval is marked as "censored", which means that this interval's capacity rate is not defined, but is above the current traffic flow value.

A well-known non-parametric method for identifying the distribution function of a random magnitude based on the analysis of censored data is known as the Kaplan-Meier method (Kaplan and Meier, 1958). Based on this method, the so-called function of survival, which describes the statistical distribution of the probability of a traffic jam at a certain traffic flow value, can be assessed as

$$
S(q)=\prod_{i: q_{i} \leq q} \frac{k_{i}-d_{i}}{k_{i}}, \quad i \in B,
$$

where $q$ is the traffic flow volume (veh/h), $q_{i}$ is the traffic flow volume in the interval $i(\mathrm{veh} / \mathrm{h}), k_{i}$ is the number of intervals with the traffic flow value, exceeding $q_{i}, d_{i}$ is the number of traffic jams at the traffic flow value $q_{i}$ and $B$ is the set of all intervals containing traffic jams.

Then the distribution function of the capacity rate is seen as an addition to the function of survival and has the form of $F_{c}=1-S(q)=1-\prod_{i: q_{i} \leq q} \frac{k_{i}-d_{i}}{k_{i}}, \quad i \in B$.

The product in this expression is reckoned with the use of all observable intervals $i$ with a flow volume value $q_{i} \leq q$, which follows a traffic jam. Usually, one observable interval containing a traffic jam is used as a single value of $q_{i}$, thus $d_{i}=1$. The distribution function reaches value 1 only if the maximum observed value of the flow volume is an unencrypted value. Otherwise, the distribution function delivers values $F_{c}(q)<1$, where $q$ is the maximum value of the volume of uncensored observations.

For parametric estimation, the type of the distribution function must be defined. The distribution parameters can be found using the maximum likelihood method. To analyze the capacity rate, the maximum likelihood function has the form

$$
L=\prod_{i=1}^{n} f_{c}\left(q_{i}\right)^{\delta_{i}} \cdot\left(1-F_{c}\left(q_{i}\right)\right)^{1-\delta_{i}},
$$

where $f_{c}\left(q_{i}\right)$ is the statistical function of the density of the capacity distribution c, $F_{c}\left(q_{i}\right)$ is the cumulative distribution function of the capacity $c, n$ is the number of intervals, $d_{i}=1$ in case if the interval contains an uncensored value and $d_{i}=0$ in case if the interval contains a censored value.

According to the study by Geistefeld and Brilon (2009), the empirical comparison of different types of statistical distributions, based on the study of different sections of the German highways, showed that the distribution of the capacity rate of highway segments can be described by the Weibull distribution. Thus, the highway capacity allocation function can be written as

$$
F_{c}(q)=1-\exp \left(-\left(\frac{q}{b}\right)^{a}\right),
$$

where $F_{c}(q)$ is the distribution function of the capacity rate, $q$ is the traffic volume of the vehicles (veh/h), $a, b$ are the Weibull distribution parameters.

The parameter $a$ of the distribution in the model (7) determines the distribution variation. According to Brilon and Geistefeldt (2010) for German highways, this parameter usually ranges from 10 to 22 . Parameter $b$ determines the systematic average value of the capacity rate caused by such constant factors as the number of lanes, the slope, the number of drivers. 
An interesting feature of this approach is the independent simulation of the capacity rate in consecutive time intervals. The choice of the duration of the simulation interval can be determined by the availability of statistical data on the state of the transport stream and the technical features of the equipment that fixes the indicators.

The natural fact, that when analyzing the capacity in the current time interval, it is reasonable to include values of the selected parameters from the previous interval, to add the process dynamics. Regardless of which model is used, to estimate the freeway section capacity, this problem has to be fixed. The approach which could provide the new model to describe the capacity based on existing models is Mathematical Remodeling (Galkin et al., 2017; Sysoev et al., 2018).

This is an approach to describe complex and / or composite systems based on the transition from mathematical or simulation models of one type to models of the other unified class. Depending on purposes and specific applied tasks, various interpretations of remodeling are possible. A theoretical model of some dependency built on the basis of its physical background, can have a structure which is quite complex and not appropriate for further analysis. In this case an array of dependency "input-output" data can be generated (which can be inaccessible under real conditions) and a simpler model of some unified structure with the required accuracy could be proposed. This is an approximation remodeling. To construct a new model a neural network and neuron-fuzzy models could be applied. In this case a remodeling has a neurostructural nature (Saraev et al., 2018).

The paper presents the algorithm used neurostructural approach to remodel freeway section capacity. It could be formulated in the following way.

Step 1. To divide the whole observed data into two subsets: (a) "congested" intervals, where the capacity rate could be estimated directly and (b) "fluid" (censored) intervals, where the capacity is obtained as Weibulldistributed random value. The criteria to separate intervals must be predefined at this step.

Step 2. Using the data sample obtained on Step 1, to train the neural network model with the predefined structure. On this step the analysis of the model accuracy must be done and corrections (in case of unsatisfied results) should be applied.

Step 3. Using the model obtained on Step 2, to estimate capacity rate within the new data set.

The proposed scheme is concerned to be a remodeling approach because it combines different ways to estimate capacity and presents a unified model to simulate this parameter.

\section{Numerical experiments}

The initial data of the analysis was obtained from a highway segment of the German federal state North Rhine Westphalia. The results were obtained on the basis of 1-minute flow volume indicators.

To remodel the freeway capacity, various different structures of neural network were investigated and it was determined, that the best result demonstrated the network with one input layer, one hidden layer consisting of 13 neurons and the output layer. In its analytic form the model can be written as

$q_{c}=\sigma\left(w_{\text {output }, 0}+\sum_{i=1}^{13} w_{\text {output }, i} \cdot \sigma\left(w_{\text {hidden }, i}+\sum_{j=1}^{3} w_{i j} x_{j}\right)\right)$,

where $q_{c}$ is a freeway section capacity (veh/h), $x_{j}=\left\{v_{\text {cars }}(t), v_{\text {cars }}(t-1)\right.$, trucks $\left.(t)\right\}$ are factors (average vehicles speed $(\mathrm{km} / \mathrm{h})$ in the current and previous time intervals and the percentage of trucks in the current interval); $w_{\text {output }, i}$ and $w_{i j}$ are identified weights on output and hidden layers respectively; $w_{\text {output }, 0}$ and $w_{\text {hidden, } i}$ are biases on output and hidden layers respectively, $\sigma(\cdot)$ is an activation function.

Numerical experiments shown, that the best results give the logistic function on a hidden layer

$$
\sigma(\text { net })=\frac{1}{1+\exp (-n e t)}
$$

and the linear function on an output layer

$\sigma(n e t)=n e t$.

To train the defined neural network model, it was prepared a data sample including input parameters mentioned above and output capacity values obtained by the presented algorithm. The criteria to specify the time interval as congested was the average speed below $70 \mathrm{~km} / \mathrm{h}$ (then the current flow rate was used as the actual capacity value).

Fig. 1 presents a comparative analysis of approaches to calculating the capacity rate of highway segment. The constructed time series of traffic flow volume of vehicles, their speed, as well as simulated capacity values correspond to a single day of observations. A total of 344 observation days were used in the study. According to the available retrospective data, the Weibull distribution parameters were established, with the help of which the capacity values were obtained. According to the concept 


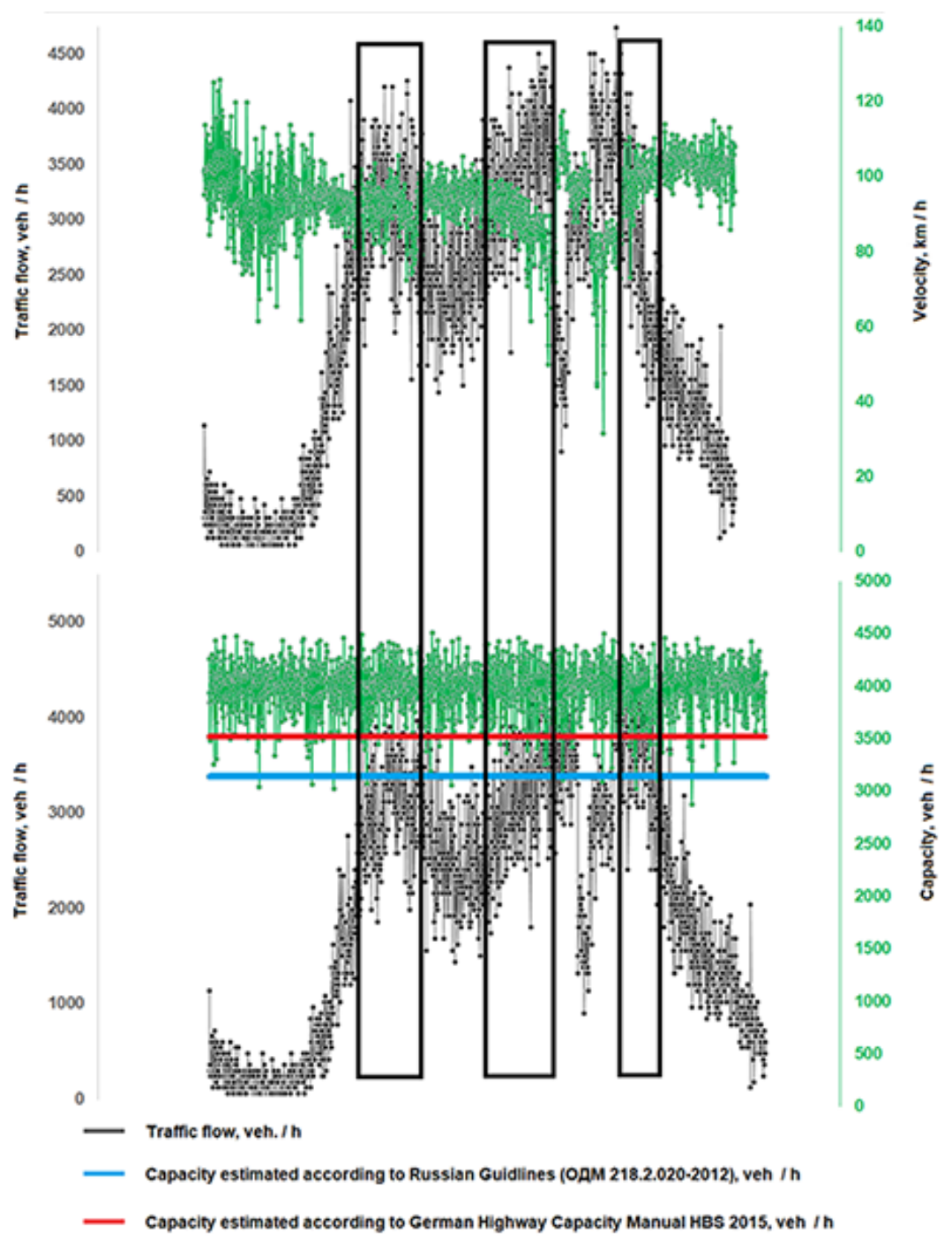

Fig. 1 Comparative analysis of approaches to estimate the capacity rate of highway segment

of ODM 218.2.020-2012 (Rosavtodor, 2012) and HBS (FGS,V 2015), constant capacity values were found. The first graph shows the dynamics of the change in traffic flow volume and the corresponding change in the flow velocity. On the basis of the analysis of this dynamics, it is possible to identify time moments with a difficult traffic flow (graphically - when the given values of speed and volume are superimposed on each other). Using this information, we turn to the lower graph. The random values obtained at each time point give a more accurate estimate of the current transport situation. To increase the accuracy of the simulation, several series of simulation experiments were carried out and average values of capacity were obtained. The proposed approach showed an accuracy of $99.5 \%$ compared to $93.55 \%$ and $83.4 \%$ using constant values according to ODM 218.2.020-2012 (Rosavtodor, 2012) and HBS (FGSV, 2015), respectively. For the standard in calculating the accuracy, the number of time moments in which the traffic jam was observed (the speed of the vehicles dropped below a certain set value) was taken.

\section{Conclusion and outlook}

Transport management issues are now particularly acute not only in Russia but also in other European countries of the EAEC and the EU. According to the concept of the development of the transport system of the Russian Federation, it is planned to integrate its domestic road networks into international ones. One of the main indicators of the functioning of the transport system is its carrying capacity. In the light of the development of the transport of goods and the comfortable movement of citizens along the highways, it is important to consider the problem at the highway level. The article presents an analysis of approaches to the issue of estimating the capacity highway 
segment in accordance with the current regulatory documents - the Russian "Methodology Recommendations for Estimating the Carrying Capacity of Highways" (Rosavtodor, 2012) and the German Handbook for Estimating Bandwidth (Handbuch für die Bemessung von Strassenverkehrsanlagen HBS (FGS,V 2015)). However, these documents recommend the use of constant capacity values for the entire simulation period of a road segment. This approach greatly reduces the accuracy of modelling. An alternative is an approach that defines the capacity as a random variable. The article presents simulation results

\section{References}

Banks, J. H. (1990) "Flow Processes at a Freeway Bottleneck", Transportation Research Record: Journal of the Transportation Research Board, 1287, pp. 20-28.

Belyh, V. S. (2008) "Концепция единогоТранспортногокодексаРо ссии : Biznes, Menedzhment i Pravo" (The concept of the unified Transport Code of Russia = Business, Management and Law), (in Russian) [online] Available at: http://bmpravo.ru/show_stat. php?stat=386 [Accessed: 10 July 2018]

Blyumin, S. L., Sysoev, A. S., Geistefeldt, J., Galkin, A. V., Saraev, P. V. (2016) "Modeling and Investigating Freeways as Systems with Variable Characteristics: Approaches in Russia and Germany", In: Proceedings of the 3rd International Conference on Traffic and Transport Engineering ICTTE, Belgrade, Serbia, pp. 991-996.

Brilon, W., Geistefeldt, J. (2010) "Überprüfung der Bemessungswerte des HBS für Autobahnabschnitte außerhalb der Knotenpunkte" (Revision of the HBS design values for basic freeways segments), Forschung Straßenbau und Straßenverkehrstechnik, Bonn, Germany, Rep. 1033. (in German)

Chen, D., Zhang, J., Wang, J., Wang, F. Y. (2003) "Freeway traffic stream modeling based on principal curves", In: Proceedings of the 2003 IEEE International Conference on Intelligent Transportation Systems, Shanghai, China, pp. 368-372.

https://doi.org/10.1109/ITSC.2003.1251979

Çodur, M. Y., Tortum, A. (2015) "An Artificial Neural Network Model for Highway Accident Prediction: A Case Study of Erzurum, Turkey", PROMET - Traffic\&Transportation, 27(3), pp. 217-225. https://doi.org/10.7307/ptt.v27i3.1551

Dharia, A., Adeli, H. (2003) "Neural network model for rapid forecasting of freeway link travel time", Engineering Applications of Artificial Intelligence, 16(7-8), pp. 607-613.

https://doi.org/10.1016/j.engappai.2003.09.011

Galkin, A., Sysoev, A., Saraev, P. (2017) "Variable structure objects remodelling based on neural networks", In: 2017 International Conference on Industrial Engineering, Applications and Manufacturing (ICIEAM), St. Petersburg, Russia, pp. 1-4. https://doi.org/10.1109/ICIEAM.2017.8076430

Geistefeldt, J., Brilon, W. (2009) "A Comparative Assessment of Stochastic Capacity Estimation Methods", In: Lam, W. H. K., Wong, S. C., Lo, H. K. Transportation and Traffic Theory 2009: Golden Jubilee, Springer, Boston, MA, USA, pp. 583-602. https://doi.org/10.1007/978-1-4419-0820-9_29 for the selected segment of the highway in the German federal state of North Rhine Westphalia. All these calculations can be carried out for any segment of the highway in the Russian Federation.

\section{Acknowledgement}

The reported study supported by the Russian Science Foundation within the project 18-71-10034. Authors are grateful to Prof. Justin Geistefeld (Ruhr-University in Bochum, Germany) for his insightful advice and anonymous reviewers for their valuable comments.

Forschungsgesellschaft für Straßen- und Verkehrswesen, FGSV (2015) "Handbuch für die Bemessung von Straßenverkehrsanlagen" (Guidelines for dimensioning road traffic facilities), FGSV-Verl., Cologne, Germany. (in German)

Kaplan, E. L., Meier, P. (1958) "Nonparametric Estimation from Incomplete Observations", Journal of the American Statistical Association, 55(282), pp. 457-481. https://doi.org/10.1080/01621459.1958.10501452

Minderhoud, M., Botma, H., Bovy, P. (1997) "Assessment of Roadway Capacity Estimation Methods", Transportation Research Record: Journal of the Transportation Research Board, 1572(1), pp. 59-67. https://doi.org/10.3141/1572-08

Rosavtodor (2012) "Отраслевой дорожный документ “Методические рекомендации по оценке пропускной способности автомобильных дорог" (ODM 218.2.020-2012 Russian National Guidelines to detect the capacity of motor roads), Federal Road Traffic Agency Rosavtodor, Moscow, Russia. (in Russian)

Minavtodor RSFSR (1982) "Руководство по оценке пропускной способности автомобильных дорог" (ODM RSFSR Guidelines to estimate the Traffic Road Capacity), The Ministry of Traffic Roads of Russian Soviet Federative Socialist Republic, Moscow, Russia. (in Russian)

Rice, J., Van Zwet, E. (2004) "A simple and effective method for predicting travel times on freeways", IEEE Transactions on Intelligent Transportation Systems, 5(3), pp. 200-207. https://doi.org/10.1109/TITS.2004.833765

Saraev, P. V., Blyumin, S. L., Galkin, A. V., Sysoev, A. S. (2018) "Neural Remodelling of Objects with Variable Structures", In: Abraham A., Kovalev S., Tarassov V., Snasel V., Vasileva M., Sukhanov A. (eds.) Proceedings of the Second International Scientific Conference "Intelligent Information Technologies for Industry" (IITI'17). IITI 2017. Advances in Intelligent Systems and Computing, Vol. 679, Springer, Cham, Switzerland, pp. 141-149.

https://doi.org/10.1007/978-3-319-68321-8_15

Sysoev, A., Blyumin, S., Saraev, P., Galkin, A. (2018) "Remodeling Approach as a Way to Automate Complicated Systems", Computer Science and Information Technologies. [online] Available at: http://csit.ugatu.su/index.php/csit/csit2017/paper/ view/5 [Accessed: 29 June 2018] 
Taylor, C., Meldrum, D. (1995) "Freeway traffic data prediction using neural networks", In: Pacific Rim TransTech Conference. 1995 Vehicle Navigation and Information Systems Conference Proceedings. 6th International VNIS. A Ride into the Future. Seattle, WA, USA, pp. 225-230.

https://doi.org/10.1109/VNIS.1995.518843

Transportation Reasearch Board, TRB (2010) "Highway Capacity Manual - HCM 2010", Transportation Research Board, National Research Council. [online] Available at: http://hcm.trb.org/?qr=1 [Accessed: 01 July 2018]

van Aerde, M. (1995) "A Single Regime Speed-Flow-Density Relationship for Freeways and Arterials", presented at the 74th Transportation Research Board Annual Meeting, Washington, DC., USA, January 1995. van Toorenburg, J. (1986) "Praktijkwaarden voor de capaciteit" (Practical Capacity Meanings), Ministerie van Verkeer en Waterstaat, Rijkswaterstaat, Dienst Verkeerskunde, Rotterdam, the Netherlands. (in Dutch)

Ventcel, E. S., Ovcharov, L. А. (2000) "Теория вероятностей и её инженерные приложения" (Probability and its Engineers Application), 2nd ed., Vysshaya shkola, Moscow, Russia. (in Russian)

Zurlinden, H. (2003) "Ganzjahresanalyse des Verkehrsflusses auf Strassen" (Whole-Year-Analysis of Highway Traffic Flow), PhD Dissertation, Ruhr-University Bochum. (in German). 